\title{
Optimization model for cropping- plan placement in paddy fields considering agricultural profit and nitrogen load management in Japan
}

\section{$\operatorname{AUTHOR}(S)$ :}

Chono, Shunsuke; Maeda, Shigeya; Kawachi, Toshihiko; Imagawa, Chie; Buma, Natsuki; Takeuchi, Junichiro

\section{CITATION:}

Chono, Shunsuke ... [et al]. Optimization model for cropping-plan placement in paddy fields considering agricultural profit and nitrogen load management in Japan. Paddy and Water Environment 2012, 10(2): 113-120

\section{ISSUE DATE:}

2012-06

URL:

http://hdl.handle.net/2433/159435

\section{RIGHT:}

The final publication is available at www.springerlink.com; This is not the published version. Please cite only the published version.; この論文 は出版社版でありません。引用の際には出版社版をご確認ご利用くだ さい。 


\title{
Optimization model for cropping-plan placement in paddy fields considering agricultural profit and nitrogen load management in Japan
}

\author{
Shunsuke Chono*, Shigeya Maeda*, Toshihiko Kawachi*, Chie Imagawa*, Natsuki Buma*,
} Junichiro Takeuchi ${ }^{*}$

*Graduate School of Agriculture, Kyoto University, Kitashirakawa-oiwake-cho, Sakyo-ku, Kyoto 606-8502, Japan

Corresponding author: Shunsuke Chono

E-mail: chono@kais.kyoto-u.ac.jp

Phone: +81-75-753-6160

Fax: +81-75-753-6349

\begin{abstract}
An optimization model for cropping-plan placement on field plots is presented for supporting decision-making on agricultural management by a farming organization. The mixed 0-1 programming technique is employed to select the next planting crop at each field plot in a holistic manner. Reduction of T-N (Total Nitrogen) discharged from field plots to the downstream end of the drainage canals is expressed as an objective function of the model in order to balance an achievement of economic goal and environmental conservation. Some Japanese governmental policies on regulating rice-cropping areas and on promoting production of particular upland field crops can be formulated in the model. A computational example of cropping-plan placement on field plots managed under integrated policies is given by operating the optimization model with various weights associated with the objectives. The procured trade-off curve and corresponding patterns of cropping-plan could be useful in the decision-making by the farming organization.
\end{abstract}

Keywords Pollutant load $\cdot$ Optimization $\cdot$ Decision support $\cdot$ Rice

\section{Introduction}


Recent decrease of total rice consumption in Japan leads to the Japanese governmental requirement that a portion of paddy fields should be converted to upland crop fields. Promotion of domestic food production is also expressed in the policy. Additionally, controlling pollutant load discharged from paddy fields is recently recognized as a key to conserve downstream water environment. Therefore, determination of cropping strategy or cropping-plan placement in a group of field plots considering both economic and environmental goals is important. Since coordination of economic and environmental goals in the agricultural decision-making is a quite complicated issue, a systematic procedure needs to be introduced to solve the problem. Employing mathematical programming, which is a kind of optimization methods, to this multiobjective decision-making problem is expected to be useful.

Some researchers have adopted mathematical programming to investigate problems on agricultural management of land or field plots. For example, Tsuchida (1992) developed a linear programming model that can determine cultivated area for rice and double-cropping of wheat and soybeans in large fields. The objective of the model is to maximize the total agricultural income under the constraints on total planting area and working hours of the farming practices. Yagi et al. (2005) presented a mixed 0-1 programming model to locate conventional rice cropping plots and ecologically-friendly winter-flooded rice cropping plots with a single objective that maximizes the agricultural gross margin. Yagi (2006) developed a methodology to provide land management alternatives in a mountainous rural area using a mixed 0-1 programming. The model attempts to maximize the total agricultural income in the area deducted by costs representing an external diseconomy (e.g., damages from diseases and wildlife animals, low efficiency of water management, etc.) of the abandonment of farming in some fields.

However, few studies have presented optimization models that produce management alternatives where the economic achievement is balanced against the environmental one. Although the optimization model presented by Yagi et al. (2005) includes constraints on winter-flooded field plot that is effective in ecological conservation, the associated physical and biochemical mechanisms are not formulated. Khanna et al. (2003) presented an integrated framework that combines a microeconomic model and a hydrological model. The framework determines a cost-effective land retirement pattern to reduce off-site sediment loadings from fields in the United States, where the retirement of cropland is one of measures against the agricultural nonpoint pollution. Yang et al. (2003) developed an integrated economic, environmental and GIS modeling framework as an extension of the study by Khanna et al. (2003) and applied it to compare cost, acreage, location and land parcel differences between a non-uniform and uniform standard across twelve 
sub-watersheds in the Illinois River Basin in the United States. Moxey and White (1994) evaluated several nitrate abatement policy instruments from a cost-effectiveness standpoint using an aggregate linear programming model to approximate producers' choice of land covers and management practices. Although studies by Khanna et al. (2003) and Yang et al. (2003) treat both economic and environmental issues in optimization considering physical pollutant transport in a large area, they are not applicable to a decision-making on crop diversification in paddy fields that are consolidated in relatively small low-land areas in Japan.

In our study, an optimization model for cropping-plan placement on consolidated field plots in Japan is developed in order to consider not only agricultural profit maximization but also nitrogen load management for environmental conservation. The two goals expressed as objective functions in the optimization model are synthesized into a single objective one using the weighting method. A demonstrative example is given to illustrate production of management alternatives on determination of planting crop at each hypothetical field plot. Environmentally conservative cropping-plan in each plot can be quantitatively examined with agricultural gross margin using the developed optimization model.

\section{Optimization Model}

A farming organization is considered which manages substantial amount of field plots (e.g., more than 20ha in total) in a lowland region. Irrigation and drainage canals in the region are assumed to be independently set for the plots as a result of farm land consolidation. Discharge from a plot is directly drained into a drainage canal since each plot is located along the drainage canal. It is also assumed that farming organization has an annual goal of yield of several crops.

The optimization model is formulated as a mixed 0-1 programming problem to determine the cropping-plan selection in each field plot in the region of interest. The selection can be represented by assigning a switching variable $I X_{i j}$ to each plot in the model, where $i$ and $j$ denote plot and cropping-plan, respectively. Since each field plot can choose only one cropping-plan, the following relation, Eq. (1), needs to be satisfied in an optimal solution when $j_{1}$-th plan is chosen in $i$-th field plot.

$$
I X_{i j}=\left\{\begin{array}{cc}
1, & j=j_{1} \\
0, & \text { otherwise }
\end{array}\right.
$$


The optimization model has two goals. One goal, $f_{1}$, is to control total nitrogen load $\left(\mathrm{g} / \mathrm{m}^{2} /\right.$ day) drained from farming plots into a downstream water body. The other goal is to improve the total agricultural gross margin (yen), which is formulated using a function $f_{2}$ below. These goals are achieved by optimizing the cropping-plan placement.

By employing the weighting method for converting the multiobjective optimization problem to a scalar one, the problem considered can be expressed as

Minimize $f=w_{1} f_{1}+w_{2} f_{2}$

where

$$
\begin{aligned}
& f_{1}=\sum_{i=1}^{N_{i}} \sum_{j=1}^{N_{j}} A_{i} L_{j} e^{-\lambda d_{i}} I X_{i j} \\
& f_{2}=-\sum_{k=1}^{N_{k}} \sum_{i \in \Omega_{k}} \sum_{j=1}^{N_{j}} A_{i}\left(P_{j k}-C_{j k}\right) I X_{i j}-S \\
& w_{1}+w_{2}=1
\end{aligned}
$$

subject to :

(i) Conditions for the switching variables of each field plot

$$
I X_{i j}=0 \text { or } 1, \quad \forall i, j
$$

(ii) Relations among the switching variables of each field plot

$$
\sum_{j=1}^{N_{j}} I X_{i j}=1, \forall i
$$

(iii) Conditions for the negative deviation of the income

$$
D_{l}^{-} \geq 0, \quad \forall l
$$

$$
\sum_{j=1}^{N_{j}} \sum_{k=1}^{N_{k}} \sum_{i \in \Omega_{k}} A_{i}\left(P_{j k l}-P_{j k}\right) I X_{i j}+D_{l}^{-} \geq 0, \quad \forall l
$$

(iv) Upper limit for the average negative deviation of income $\frac{1}{N_{l}} \sum_{l=1}^{N_{l}} D_{l}^{-} \leq \alpha$

where $i$ is the subscript for field plot; $j$ is the subscript for cropping-plan; $I X_{i j}$ is the 
integer decision variable for cropping-plan $j$ selected at field plot $i ; w_{1}$ and $w_{2}$ are the weight coefficients; $N_{i}$ is the number of field plots; $N_{j}$ is the number of cropping-plans; $L_{j}$ is the unit loading factor of T-N load discharged into drainage canal from the field plot where the cropping-plan $j$ is selected $\left(\mathrm{g} / \mathrm{m}^{2} /\right.$ day); $\lambda$ is the self-purification coefficient of T-N load in drainage canals $\left(\mathrm{m}^{-1}\right) ; d_{i}$ is distance measured along the course of drainage canal from the outfall of the field plot $i$ to the downstream end of the main drainage canal (m); $A_{i}$ is the area of the field plot $i\left(\mathrm{~m}^{2}\right) ; k$ is the subscript for field zones; $N_{k}$ is the number of field zones; $\Omega_{k}$ is the subscript set of field plots in Zone $k ; P_{j k}$ is the given expected (e.g., recent five-year-average) income from the plot in Zone $k$ following the cropping-plan $j$ $\left(\right.$ yen $\left./ \mathrm{m}^{2}\right) ; C_{j k}$ is the supposed production cost in plot in Zone $k$ that takes the plan $j$ $\left(\right.$ yen $\left./ \mathrm{m}^{2}\right) ; S$ is the total subsidies (yen); $l$ is the subscript for each of the past years; $N_{l}$ is the number of the past years where income data are obtained; $D_{l}^{-}$is the sum of negative deviation of income from its average in the year $l$ (yen); $P_{j k l}$ is the gross income from the field plot in Zone $k$ per area in the year $l$, resulting from taking the cropping-plan $j$ $\left(\right.$ yen $\left./ \mathrm{m}^{2}\right) ; \alpha$ is the upper limit for the average of $D_{l}^{-}$(yen). It is noted that variables except $I X_{i j}$ and $D_{l}^{-}$are all constants and given. In Eq. (3), decrease of TN by settlement and deoxygenation along the drainage canals is assumed to occur by following the distance-related first-order kinetics which is conventionally assumed. The value of self-purification coefficient, $\lambda$, is assumed uniform for simplicity in this study. The branch-and-bound method is adopted to solve the mixed 0-1 programming problem.

\section{Demonstrative Example}

Application to field plots in Japan

In field plots that a group farming organization owns, the following farming practices for the crops are assumed to be standardized: (1) Rice seedlings are transplanted in May, and the crop is harvested in September; (2) Seeds of wheat are sown in November, and the crop 
is harvested in next June; (3) Soybeans are sown in June and the crop is harvested in November. Note that soybeans can be sown after wheat is cultivated in a field plot. Although all the field plots had been developed for rice planting, some plots, whose total area is obligatory allotted by the Government to the farming organization, are set aside for planting other plants, i.e., wheat and soybeans. Since environmental pollution caused by agricultural discharges is a great concern for the organization, as well as its total profit, an environmentally- and economically-sound cropping-plan is required. Therefore, the optimization model is used to design a plan that determines which crop(s) should be planted in each plot after this November.

It is assumed that the group farming organization can select one of the four plans, listed in Table 1, for each field plot. For example, in a plot of interest, the plan 'P1' means that rice was planted this year, and rice seedlings will be transplanted next April. The plan 'P2' means that rice was planted in the plot this year, but seeds of wheat will be sown right after harvesting of rice, and then soybeans will be planted next June just after harvesting of wheat. The plans 'P3' and 'P4' shown in Table 1 are defined similarly. By solving the optimization model, the selection of a plan 'P1', 'P2', 'P3' or 'P4' is conducted with the associated switching variable $I X_{i j} \quad(j=1,2,3$ and 4) for each field plot $i$, respectively.

Some site-specific constraints concerning the farming practice are added to the optimization model. Relations among the switching variables of each field plot according to the lastly-planted crop are introduced as shown below.

$$
\begin{aligned}
& \sum_{j \in\{1,2\}} I X_{i j}=1, \quad \forall i \in \Omega^{r} \\
& \sum_{j \in\{3,4\}} I X_{i j}=1, \quad \forall i \in \Omega^{c}
\end{aligned}
$$

where $\Omega^{r}$ and $\Omega^{c}$ are the subscript sets of field plots where lastly-planted crop are rice (P1 and P2) and soybeans (P3 and P4), respectively. Lower limit for the rate of areas of upland fields converted from paddy fields (employing plans P2 and P4) to the total area is also formulated as

$$
\sum_{i=1}^{N_{i}} \sum_{j \in\{2,4\}} A_{i} I X_{i j} / \sum_{i=1}^{N_{i}} A_{i} \geq \frac{\beta}{100}
$$

where $\beta$ is the lower limit for the rate of total area of upland crop fields to the total area of whole plots in the next stage (\%).

The optimization model is applied to hypothetical 80 field plots in Japan where a group farming organization can choose plans listed in Table 1 for each plot with two goals represented in the objective functions. The field plots and related drainage canals are 
depicted in Fig. 1. The typical size of the plot in Japan (100m by 30m) is assumed and area of all the plots is 24 ha in total. Five-year incomes per unit area given in Table 2 are prepared for this computational example. Values of $P_{j k l}(j=1,3)$ in Table 2 are assumed based on the statistics of gross margin (net sales revenue) per unit area of rice cropping except in Hokkaido Prefecture from 2002 to 2006, released by Cabinet Secretariat Statistics Department of MAFF of Japan (2007). Values of $P_{j k l}(j=2,4)$ in Table 2 are the same kind of data for wheat and soybeans (Cabinet Secretariat Statistics Department of MAFF of Japan (2007)). In Table 2, values of $P_{3 k l}(l=1,2, \cdots, 5)$ are greater than values of $P_{1 k l}$ $(l=1,2, \cdots, 5)$, which is consistent with the data observed in the fields in Niigata (Tsuchida, 2003), that is, unit yield of rice in the plot following P3 is greater than that in the plot which adopts P1. Material costs in Table 4 are substituted for production costs in the model in this example since current production costs of rice often exceed sales revenues, which do not contain the subsidy, in Japan. The values of $C_{j k}(j=1,3)$ in Table 4 are given based on a material cost per unit area of rice cropping except in Hokkaido Prefecture in 2007 (Cabinet Secretariat Statistics Department of MAFF of Japan (2008)) and $C_{j k}(j=2,4)$ are given based on the same kind data for wheat and soybeans cropping (Cabinet Secretariat Statistics Department of MAFF of Japan (2008)). Expected incomes per unit area, $P_{j k}$, are given as average value of $P_{j k l}(l=1,2, \cdots, 5)$, as indicated in Table 3. Cost of fertilizer is reduced by employing P3 compared with P1, which results in lower material costs of $C_{3 k}$ in Table 4. Unit loading factors, the self-purification coefficient of T-N load and other parameters are shown in Table 5. Unit loading factors are determined based on Life Circumstance Department's Kasumigaura Lake Management Division of Ibaraki Prefecture (2001). The self-purification coefficient and the other parameters are assigned as reasonable values in Table 5.

\section{Agricultural Policy}

According to the approved budget for 2010 in Japan (the Japanese Government (2009)), the Ministry of Agriculture, Forestry and Fisheries (MAFF) starts projects for the direct 
payments to particular farmers and farming organizations (the Ministry of Agriculture, Forestry and Fisheries (2009)). In this study, the following principal projects (Project-1 through -3 ) are mentioned to consider in the optimization model.

Project-1: The direct financial support project to increase food self-sufficiency by promoting planting particular crops

The government gives direct payments to commercial farm households which convert paddy fields into multi-purpose ones and produce particular crops (e.g., barley, wheat, soybeans, rice given to animals or used as biofuel, etc.) in order to improve the self-sufficiency of food in Japan. Since the selling price of those crops is lower than that of rice in general, the subsidy is expected to compensate for the decrease of income caused by planting the crops other than rice in the fields.

Project-2: The direct financial support project to increase food self-sufficiency for rice

The government offers direct payments to commercial farm households and group farming organizations which follow the rice production adjustment program. The income compensation is composed of fixed and variable parts. Thus they can receive at least 15 yen per $1 \mathrm{~m}^{2}$ (paddy field) as the fixed payment. If a current year's wholesale price of rice is lower than a standard price (average price in the past three years), the variable part (yen per $1 \mathrm{~m}^{2}$ ) compensates for the loss of selling. It is noted that the payment rate is applied to upper portion of the area greater than $1,000 \mathrm{~m}^{2}$.

Project 3: The compensation project for less favored farming conditions

The compensation project for less favored farming conditions offers two subsidies, one of which is determined from planted area in the past years and the other is from current year's yield and its quality. The objective crops are barley, wheat and soybeans. Farmers and group farming organizations need to satisfy some managerial requirements in order to receive the subsidies.

Formulation of subsidies

The subsidies of the Projects-1, 2 and 3 are expressed as $S_{1}, S_{2}$ and $S_{3}$ in Eqs. (15)-(17), respectively. The variable part of subsidy in Project- 2 is not formulated. Thus $S$ in the 
second objective function Eq. (4) can be computed as a sum of S1, S2 and S3, shown in Eq. (14).

$$
\begin{aligned}
& S=S_{1}+S_{2}+S_{3} \\
& S_{1}=S_{1} \sum_{i=1}^{N_{i}} \sum_{j=\{2,4\}} A_{i} I X_{i j} \\
& \left.S_{2}=S_{2}\left\{\sum_{i=1}^{N_{i}} \sum_{j=\{1,3\}} A_{i} I X_{i j}-1000 N_{h}\right\} \quad \text { (if } \sum_{i=1}^{N_{i}} \sum_{j=\{1,3\}} A_{i} I X_{i j}-1000 N_{h}>1000 N_{h}\right) \\
& S_{3}=\sum_{k=1}^{N_{k}} \sum_{i \in \Omega_{k}} A_{i}\left\{I X_{i 2}\left(s_{3}^{W} \bar{Y}_{k}^{r W}+s_{3}^{S} \bar{Y}_{k}^{r S}\right)+I X_{i 4}\left(s_{3}^{W} \bar{Y}_{k}^{c W}+s_{3}^{S} \bar{Y}_{k}^{c S}\right)\right\}+A^{S_{3}}\left(s_{3}^{W}+s_{3}^{S}\right)
\end{aligned}
$$

where $s_{1}$ and $s_{2}$ are the subsidies per unit area of the Project-1 and $2\left(\mathrm{yen} / \mathrm{m}^{2}\right)$, respectively; $N_{h}$ is the number of families which join the farming organization; $s_{3}^{W}$ and $s_{3}^{S}$ are the subsidies of Project-3 based on qualitative and quantitative standards of wheat and soybeans (yen/kg), respectively; $s_{3}^{w}$ and $s_{3}^{s}$ are the subsidies of Project-3 based on the area where wheat and soybeans were cropped in the past years $\left(\mathrm{yen} / \mathrm{m}^{2}\right)$, respectively; $\bar{Y}_{k}^{r W}$ and $\bar{Y}_{k}^{r S}$ are the expected yields of wheat and soybeans at the field plots in Zone $k$ where rice was lastly cropped $\left(\mathrm{kg} / \mathrm{m}^{2}\right)$, respectively; $\bar{Y}_{k}^{c W}$ and $\bar{Y}_{k}^{c S}$ are the expected yields of wheat and soybeans at the field plots in Zone $k$ where crops were lastly harvested $\left(\mathrm{kg} / \mathrm{m}^{2}\right)$, respectively; $A^{s_{3}}$ is the area of field plots where multi-cropping have been conducted in the past years and the subsidy in Project-3 is determined $\left(\mathrm{m}^{2}\right)$. Coefficients regarding the subsidies are assigned referring to the Japanese Government (2009) and the Ministry of Agriculture, Forestry and Fisheries (2009) and summarized in Table 6.

\section{Results and Discussion}

The FORTRAN code developed by Ibaraki (Ibaraki and Fukushima, 1991) is used to solve the problem [Eqs. (2)-(17)]. Since the optimization model is a bi-objective programming problem, drawing the trade-off curve between objectives is meaningful by procuring noninferior solutions with various weight values of $w_{1}$ and $w_{2}$. Fig. 2 shows the trade-off relation between the discharged pollutant load from the total field plots and the total 
expected gross margin in the farming organization. Fig. 3 shows various procured optimal placement of the cropping-plans to the plots. Fig. 4 represents the relation among optimal objective values and given weights. Regarding $w_{1}$ smaller than 0.900 , the same optimal plan placement and objective values as those with $w_{1}=0.900$ shown in Figs. 3 and 4 is obtained.

As shown in Fig. 2, the expected gross margin is proportional to the discharged pollutant load. However, the gradient of the trade-off curve fitted to the plots in this figure varies over the range of discharged load shown in the horizontal axis. For example, when $w_{1}$ decreases from 1.0 to around 0.985 , even though the pollutant load remains almost the same, the expected gross margin increased more than 0.3 million yen (see Figs. 2 and 4). This is attributed to the fact that more number of plots that employ P2 are arranged to Zones 2 and 4 where the profit values of $P_{2 k l}(k=2,4 ; l=1,2, \cdots, 5)$ are large compared with $P_{2 k l}(k=1,3 ; l=1,2, \cdots, 5)$ for Zones 1 and 3 (see Table 2 and (i)-(1) in Fig. 3).

On the other hand, the small gradient of the right part of the curve in Fig. 2 indicates that decrease of pollutant load less affects decrease of the gross margin. Therefore, the cropping-plans appearing around the right part of the trade-off curve (corresponding plans are shown in (a) and (b) in Fig. 3) may be favored by decision-makers who insist the economic achievement.

The optimal cropping-plan placement shown in Fig. 3 is certainly affected by many factors such as plot-based income and material costs, unit loading factor, flow length of discharged load from the plot to the downstream end of the drainage canal, etc. However, some tendencies can be observed in the twelve allocations in Fig. 3. As can be expected from Eqs. (2)-(4), giving larger values to $w_{1}$ emphasizes the objective $f_{1}$, i.e., minimization of the total discharged load from the plots. Since unit loading factors of paddy field in the next stage, $L_{1}$ and $L_{2}$, are smaller than those of upland crop field, shown in Table 5, the more close to $1 w_{1}$ becomes among the noninferior solutions, the more plots where rice is planted (or 'white rectangle' in Fig. 3) appear. As $w_{1}$ increases from 0.900 to 0.964 ((a) through (e) in Fig. 3), only plots whose lastly planted crop is soybeans are sequentially selected to adopt the plan P3. This is because changing crops from soybeans-wheat to rice is the most cost-effective for the pollutant load reduction as shown in Tables 2, 3 and 5. Moreover, plots in Zone 3 is firstly chosen as $w_{1}$ increases in the range of 0.900 through 0.964 , which is mainly due to the fact that $P_{3 k}-C_{3 k}(k=3)$ has the maximum among $P_{3 k}-C_{3 k}(k=1,2,3$ and 4$)$. Using the obtained trade-off relation and the concrete plan placement, the farming organization could determine cropping strategies more rationally.

The trade-off relation shown in Figs. 2 and 4 provides a decision-maker of the farming 
organization with meaningful information for selecting one of the solutions with various weight values of $w_{1}$ and $w_{2}$. If the decision-maker is environmentally conscious, the solution with as large weight value of $w_{1}$ as possible would be selected by the decision-maker, who also considers the total expected gross margin indicated in Figs. 2 and 4. It is adequate from an environmental impact perspective to select the solution with as large weight value of $w_{1}$ as possible or the maximum value $\left(w_{1}=1\right)$. However, the decision-maker who emphasizes economic efficiency would select normally the solution with the minimum weigh value of $w_{1}$ and expect the maximum total gross margin. When environmental conservation should be considered, the decision-maker would choose the solution with the acceptable weight value of $w_{1}$ evaluating a decrease of the total expected gross margin represented in Figs. 2 and 4. Thus, the optimization model could serve as a management decision-making support tool for various decision makers of farming organization which place an emphasis on environmental conservation or economic efficiency.

\section{Conclusions}

An optimization model is developed for cropping-plan placement on the paddy field plots that a group farming organization manages in a small low-land region in Japan. The optimization model, formulated as a mixed 0-1 programming problem, aids to choose the best cropping-plan at each field plot, based on economic and environmental goals. Pollutant load discharged from the plots to the downstream can be controlled by minimization of the first objective function representing the distance-related self-purification in the drainage canals. The optimization model is applied to a hypothetical agricultural field containing 80 field plots. The current Japanese governmental policies for increasing food production are expressed in the terms on subsidies and the constraint that limits the area where rice can be cropped. The curve of trade-off between the total expected gross margin and total discharged pollutant load is depicted by operating the optimization model in order to explore more effective selection of cropping-plan, or management alternative in the decision-making process. 
Decision-make's preference to the two goals assumed in this study would be reflected in the selection of the management alternative when the optimization model is applied to a real existing farming organization. The cost-effectiveness indicated by the trade-off curve would practically be useful in choosing a solution which places an emphasis on environment conservation or economic efficiency by following decision-maker's preference. Since the conflict between the economic goal and pollutant load reduction in agriculture is a worldwide problem, the framework presented in this paper would be extended to applications in many low-land agricultural regions in other countries.

\section{References}

Cabinet Secretariat Statistics Department of Ministry of Agriculture, Forestry and Fisheries of Japan (2007) Management statistics by farming pattern under private management (rice farming) in 2006. Tokyo (in Japanese)

Cabinet Secretariat Statistics Department of Ministry of Agriculture, Forestry and Fisheries of Japan (2008) Production cost statistics under private management (rice, wheat and soybeans) in 2007. Tokyo (in Japanese)

Ibaraki T, Fukushima M (1991) Fortran 77 optimization programming. Iwanami Computer Science Series, Iwanami, Tokyo, pp 421-452 (in Japanese)

Life Circumstance Department's Kasumigaura Lake Management Division of Ibaraki Prefecture (2001) 4th Water Quality Conservation Plan for Kasumigaura Lake. Mito (in Japanese)

Khanna M, Yang W, Farnsworth R, Önal H (2003) Cost-effective targeting of land retirement to improve water quality with endogenous sediment deposition coefficients. American Journal of Agricultural Economics, 85(3), pp 538-553

Moxey A, White B (1994) Efficient compliance with agricultural nitrate pollution standards. Journal of Agricultural Economics, 45(1), pp 27-37

The Japanese Government (2009) The budget proposal for 2010. http://www.mof.go.jp/seifuan22/yosan.htm (in Japanese)

The Ministry of Agriculture, Forestry and Fisheries (2009) The system of the individual income compensation. http://www.maff.go.jp/j/seisaku/kobetu_hosyo/index.html (in Japanese)

Tsuchida S (1992) Conditions of development of rice-barley-soybeans cropping in the high quality rice production area: application of linear programming to large paddy farming. Japanese Journal of Farm Management, 30(2), pp 46-55 (in Japanese)

Yagi H, Mineta T, Ashida T, Kurita H (2005) Farmland plot allocation for environmental 
conservation rice production considering irrigation system: a case study on winter-flooded rice fields. Journal of Rural Planning Association, 24, pp 67-72 (in Japanese)

Yagi H (2006) An empirical application of the linear programming model for agricultural land use planning: through the valuation of negative externalities caused by farmland abandonment in marginal areas. Journal of Rural Economics, 78(1), pp 12-21 (in Japanese)

Yang W, Khanna M, Farnsworth R, Önal H (2003) Integrating economic, environmental and GIS modeling to target cost effective land retirement in multiple watersheds. Ecological Economics, 46, pp 249-267

\section{Figure Caption}

Fig. 1 Hypothetical field plots and drainage canals

Fig. 2 Trade-off curve between total discharged pollutant load and total expected gross margin

Fig. 3 Optimal placement of the cropping-plans on field plots computed with various values of $w_{1}$

Fig. 4 Relations among optimal objective values and $w_{1}$ 
Fig. 1

Field plot where soybeans were lastly planted

$\square$ Field plot where rice was lastly planted

1, 2,3, 4 Zone number

Drainage canal

V Downstream end of main drainage canal

$\rightarrow \quad$ Flow direction

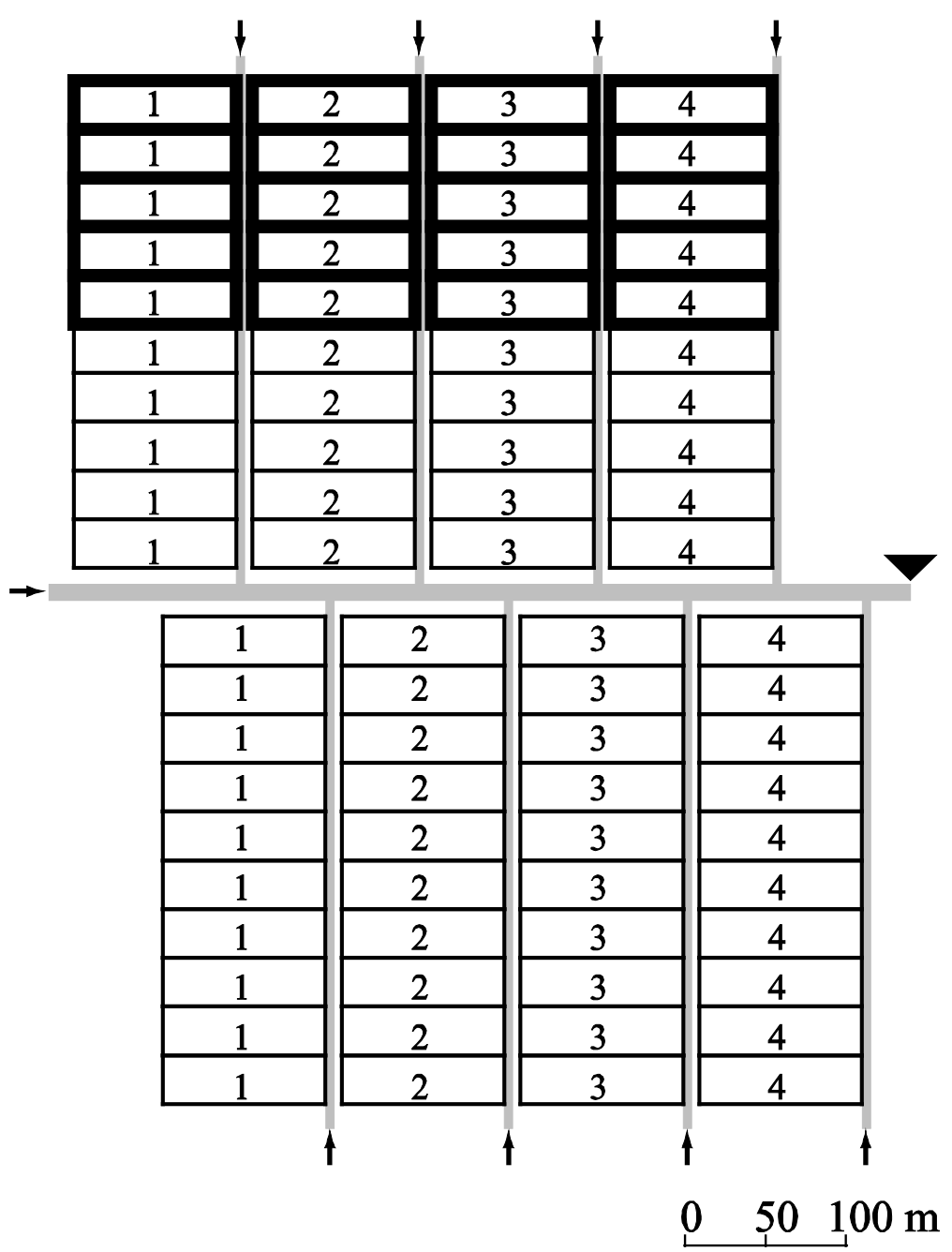


Fig. 2

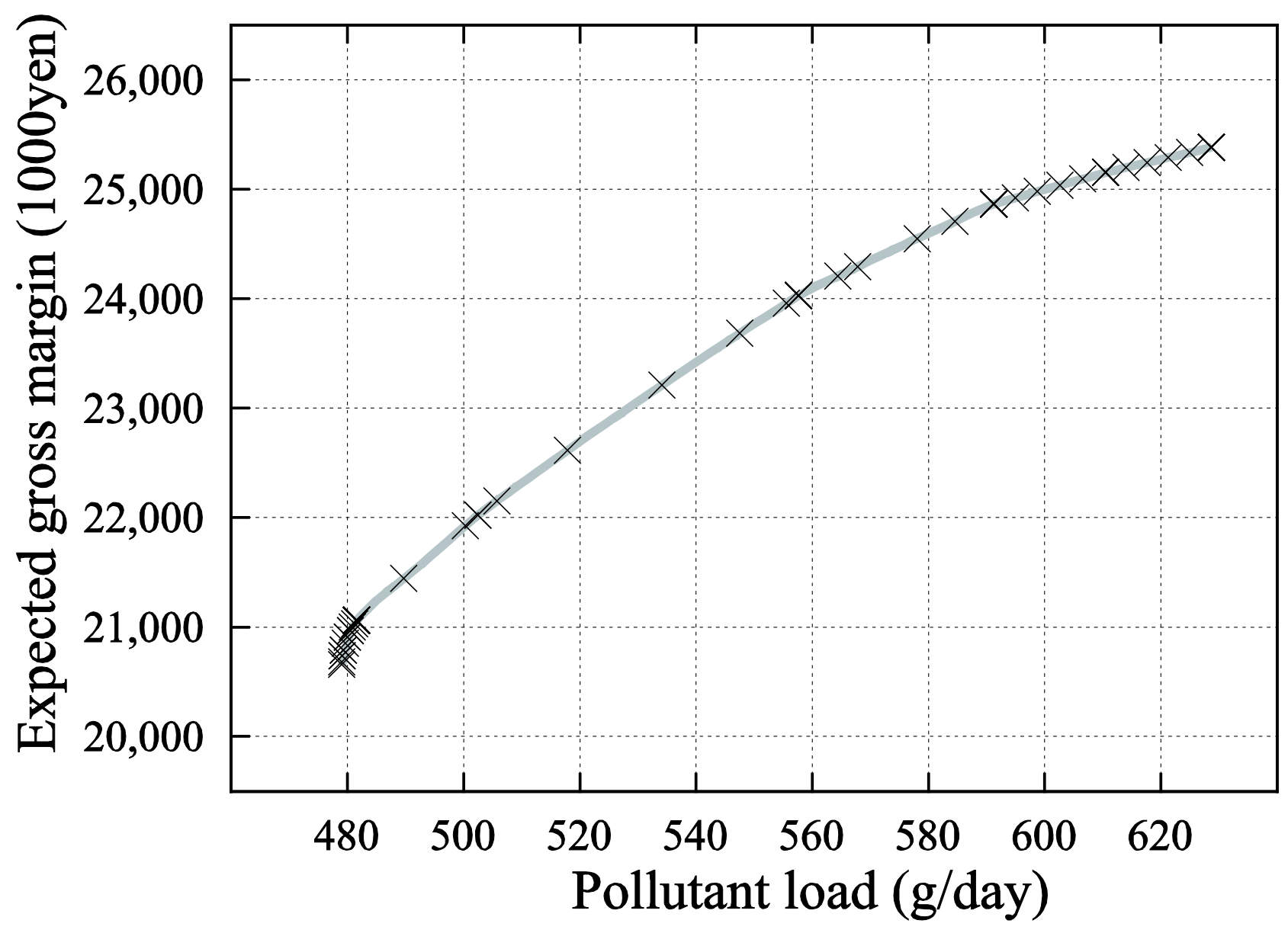


Fig. 3

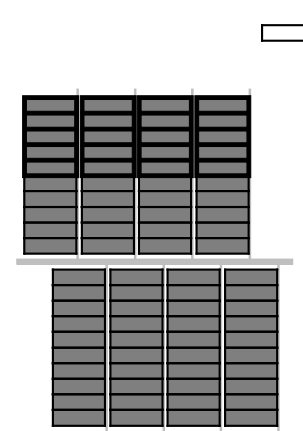

(a) $w_{1}=0.900$

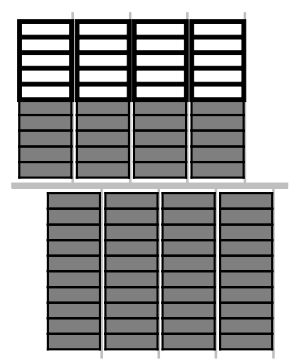

(e) $w_{1}=0.964$

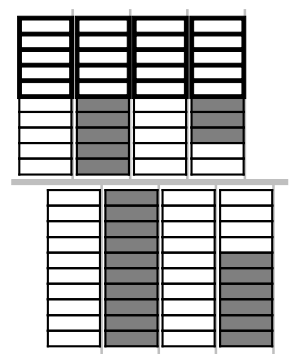

(i) $w_{1}=0.979$

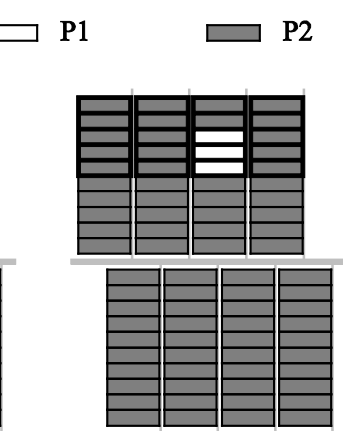

(b) $w_{1}=0.927$

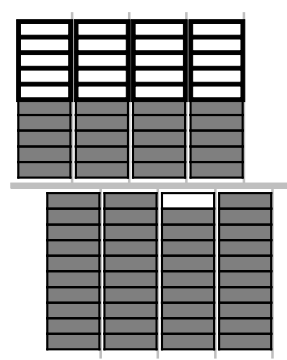

(f) $w_{1}=0.971$

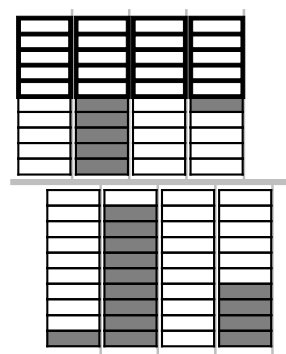

(j) $w_{1}=0.988$

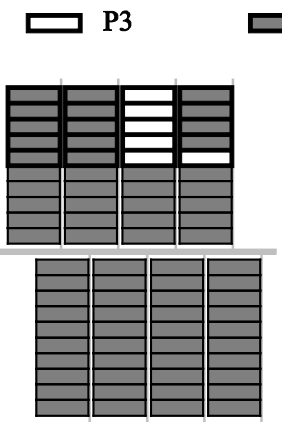

(c) $w_{1}=0.936$

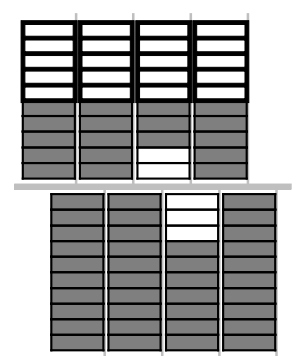

(g) $w_{1}=0.972$

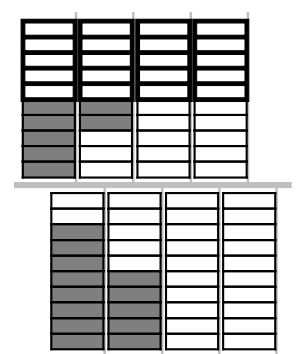

(k) $w_{1}=0.999$

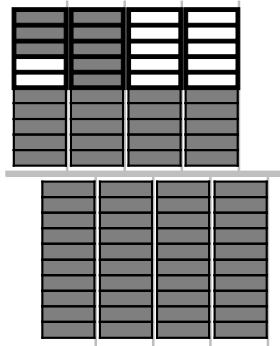

(d) $w_{1}=0.960$

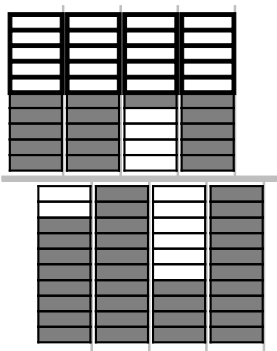

(h) $w_{1}=0.973$

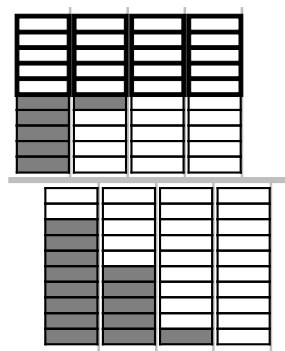

(l) $w_{1}=1.00$ 
Fig. 4

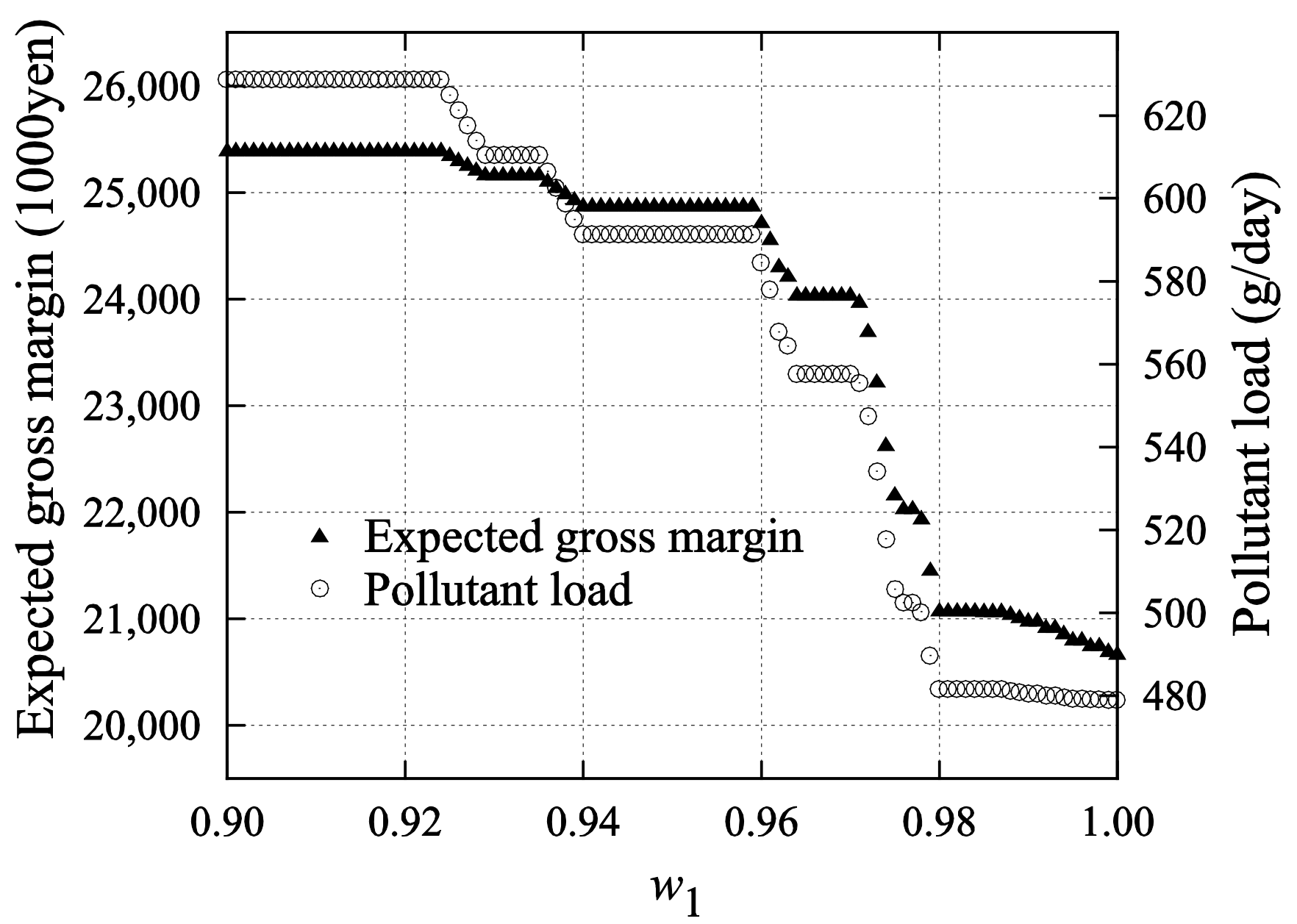


Table 1 Plans for planting crops in the next stage and associated zero-one decision variables

\begin{tabular}{cllc}
\hline Plan & $\begin{array}{l}\text { Lastly planted } \\
\text { (up to this November) }\end{array}$ & Planted next & Subscript $j$ of \\
& & & $I X_{i j}$ \\
\hline P1 & Rice & Rice & 1 \\
P2 & Rice & Wheat - soybeans & 2 \\
P3 & Soybeans & Rice & 3 \\
P4 & Soybeans & Wheat - soybeans & 4 \\
\hline
\end{tabular}


Table 2 Unit five-year income per area

\begin{tabular}{|c|c|c|c|c|c|}
\hline \multicolumn{6}{|c|}{$P_{j k l}\left(\right.$ yen $\left./ \mathrm{m}^{2}\right)$} \\
\hline \multirow[t]{2}{*}{$j$} & \multirow[t]{2}{*}{ l } & \multicolumn{4}{|c|}{$k$} \\
\hline & & 1 & 2 & 3 & 4 \\
\hline \multirow{5}{*}{1} & 1 & 126.914 & 118.245 & 130.554 & 129.069 \\
\hline & 2 & 150.373 & 145.933 & 162.753 & 148.915 \\
\hline & 3 & 119.425 & 114.676 & 122.63 & 117.281 \\
\hline & 4 & 117.299 & 118.349 & 118.94 & 110.933 \\
\hline & 5 & 113.415 & 110.293 & 109.379 & 119.055 \\
\hline \multirow{5}{*}{2} & 1 & 86.769 & 95.582 & 83.206 & 99.967 \\
\hline & 2 & 90.175 & 93.872 & 99.76 & 96.767 \\
\hline & 3 & 97.785 & 95.078 & 86.087 & 98.814 \\
\hline & 4 & 87.791 & 93.847 & 100.639 & 110.165 \\
\hline & 5 & 79.986 & 80.795 & 88.408 & 77.711 \\
\hline \multirow{5}{*}{3} & 1 & 134.648 & 130.53 & 142.598 & 139.39 \\
\hline & 2 & 156.207 & 149.887 & 177.142 & 152.933 \\
\hline & 3 & 132.428 & 133.166 & 132.128 & 117.719 \\
\hline & 4 & 118.437 & 121.127 & 122.746 & 117.605 \\
\hline & 5 & 111.542 & 103.404 & 119.858 & 123.024 \\
\hline \multirow{5}{*}{4} & 1 & 88.587 & 83.727 & 94.038 & 90.927 \\
\hline & 2 & 103.495 & 107.706 & 87.61 & 84.494 \\
\hline & 3 & 81.308 & 92.424 & 86.256 & 87.154 \\
\hline & 4 & 88.548 & 90.671 & 86.69 & 81.794 \\
\hline & 5 & 98.706 & 89.343 & 90.168 & 83.651 \\
\hline
\end{tabular}

Source: Cabinet Secretariat Statistics Department of MAFF of Japan (2007) 
Table 3 Unit expected income per area

\begin{tabular}{ccccc}
\hline \multicolumn{5}{c}{$P_{j k}\left(\mathrm{yen} / \mathrm{m}^{2}\right)$} \\
\hline$j$ & \multicolumn{5}{c}{$k$} \\
\cline { 2 - 5 } & 1 & 2 & 3 & 4 \\
\hline 1 & 125.485 & 121.499 & 128.851 & 125.051 \\
2 & 88.501 & 91.835 & 91.62 & 96.685 \\
3 & 130.652 & 127.623 & 138.894 & 130.134 \\
4 & 92.129 & 92.774 & 88.952 & 85.604 \\
\hline
\end{tabular}

Table 4 Unit material costs per area

\begin{tabular}{cc}
\hline & $C_{j k}\left(\mathrm{yen} / \mathrm{m}^{2}\right)$ \\
\hline$j$ & $k$ \\
\cline { 2 - 2 } & $1,2,3,4$ \\
\hline 1 & 75.183 \\
3 & 72.130 \\
4 & 69.161 \\
\hline
\end{tabular}

Source: Cabinet Secretariat Statistics Department of MAFF of Japan (2008) 
Table 5 Other parameters

\begin{tabular}{cc}
\hline$L_{1}\left(\mathrm{mg} / \mathrm{m}^{2} / \text { day }\right)^{\mathrm{a}}$ & 2.24 \\
$L_{2}\left(\mathrm{mg} / \mathrm{m}^{2} / \text { day }\right)^{\mathrm{a}}$ & 2.24 \\
$L_{3}\left(\mathrm{mg} / \mathrm{m}^{2} / \text { day }\right)^{\mathrm{a}}$ & 2.99 \\
$L_{4}\left(\mathrm{mg} / \mathrm{m}^{2} / \text { day }\right)^{\mathrm{a}}$ & 3.75 \\
$\lambda\left(\mathrm{m}^{-1}\right)$ & 0.0005 \\
$N_{h}$ & 4 \\
$\alpha($ yen $)$ & $1,500,000$ \\
$\beta(\%)$ & 25.0 \\
\hline
\end{tabular}

${ }^{a}$ Source: Life Circumstance Department's Kasumigaura Lake Management Division of Ibaraki Prefecture (2001)

Table 6 Subsidy rates

\begin{tabular}{ccc}
\hline$s_{1}$ & $\left(\right.$ yen $\left./ \mathrm{m}^{2}\right)$ & 50.00 \\
$s_{2}$ & $\left(\right.$ yen $\left./ \mathrm{m}^{2}\right)$ & 15.00 \\
$S_{3}^{W} \quad($ yen $/ \mathrm{kg})$ & 35.17 \\
$S_{3}^{S} \quad($ yen $/ \mathrm{kg})$ & 45.60 \\
$S_{3}^{w} \quad\left(\right.$ yen $\left./ \mathrm{m}^{2}\right)$ & 27.74 \\
$S_{3}^{s} \quad\left(\right.$ yen $\left./ \mathrm{m}^{2}\right)$ & 20.23 \\
\hline
\end{tabular}

Source: The Japanese Government (2009) 